\title{
Congenital Indifference to Pain: A Report of Three Cases from Pakistan
}

\author{
Ali Raza QURESHI, Saeed Bin AYAZ, Atif Ahmed KHAN, Zaheer Ahmed GILL \\ Armed Forces Institute of Rehabilitation Medicine (AFIRM), Rawalpindi, Pakistan
}

\begin{abstract}
Congenital indifference to pain is a rare disease defined by the failure to react to painful stimuli. Patients often present in early childhood with multiple self-inflicted injuries and damaged dentition. The response to other sensory modalities remains intact. Patients have normal nerve conduction and electromyography, as well as normal nerve biopsy. The disease is diagnosed after excluding congenital insensitivity to pain, fragile X-syndrome, syringomyelia, and pain asymbolia. Early diagnosis can reduce recurrent injuries and avoid unnecessary investigations. Here we present three patients with congenital indifference to pain who were referred to our institute for electrophysiological evaluation and found to have this disease. Keywords: Pain, congenital indifference to pain, congenital insensitivity to pain, nerve conduction studies, electromyography, Pakistan
\end{abstract}

\section{Introduction}

Pain is generally described as an unpleasant sensation or a distressing experience, but it is actually the natural defense from physical harm. Absence of pain perception makes a person prone to repeated soft tissue damage, bone fractures, and rapidly degenerating joints. Congenital indifference to pain is a rare syndrome, which characteristically features failure to exhibit aversion to or withdrawal from painful stimuli, despite not having neurological abnormalities in pain pathways (1). Children affected by this syndrome present with unusual injuries during their early years, which are generally caused by repetitive selfinflicted damage (2). The diagnosis depends on clinical features, as well as biochemical, electrophysiological, pathological, and genetic testing. Here we report three patients who were electrophysiologically evaluated at the electrodiagnostic department of our institute and who were found to have congenital indifference to pain.

\section{Case Reports}

Case 1

A 9-month-old female infant was referred to our institute for electrophysiological evaluation. She had a history of abnormal biting and self-mutilating behavior that had damaged her tongue, teeth, lips, and fingers. She was the first-born to a consanguineous marriage and had no siblings. On examination, she was sitting comfortably in her mother's lap and had excessive dribbling of saliva from the mouth. Her face was not dysmorphic. She had bitten her tongue and lower lip. Her two upper incisors were missing (Figure 1). There were bilateral bite marks on her fingers. She did not respond to pinprick or exposure to hot and cold stimuli. Her joint examination was normal. Muscle tone and deep tendon reflexes (DTR) were also normal.

Laboratory investigations of this patient showed normal complete blood count and serum uric acid levels. Magnetic resonance imaging (MRI) of her brain with and without contrast was also normal. Her electrophysiological evaluation was 
performed on a XLTEK Neuromax 1004 Electromyography (EMG) Unit using surface electrodes for nerve conduction studies (NCS) and concentric needle electrodes for EMG. Motor NCS revealed normal latencies, amplitudes, and conduction velocities in median, ulnar, and radial nerves in the upper limbs as well as the common peroneal and tibial nerves in the lower limbs. Sensory NCS revealed normal latencies, amplitudes, and conduction velocities in median, ulnar, and radial nerves in the upper limbs and sural nerves in the lower limbs. The child did not respond to electrical stimulation but started crying on EMG. EMG showed no involuntary activity and normal morphology and recruitment of motor unit action potentials in key sampled muscles of the four limbs. The patient was given an electrophysiological impression of a normal study, and a clinical correlation for a diagnosis of congenital indifference to pain was suggested. Informed consent was obtained from the mother of the patient for publication of this case report and the accompanying image.

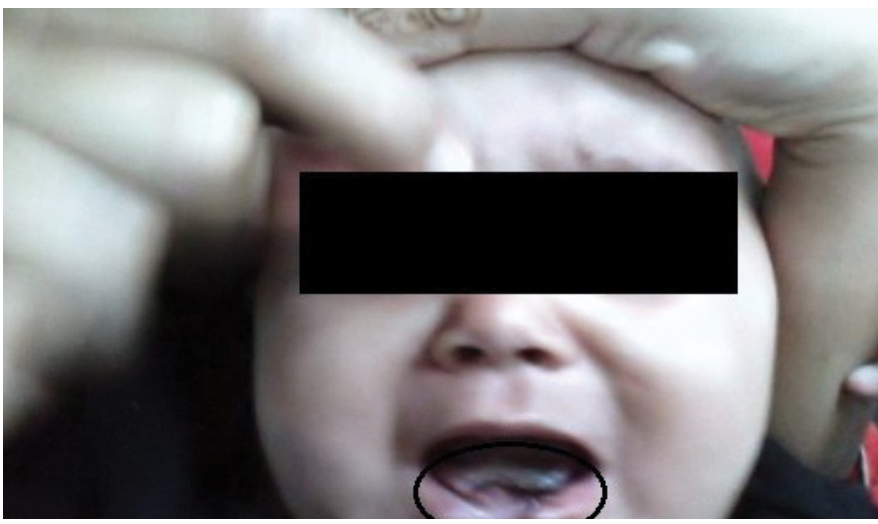

Figure 1. First case: A 9-month-old female infant showing bitten tongue and lower lip

\section{Case 2}

A 30-month-old male presented with a three month history of pressure ulcers on both knees. He had a history of repeated tooth loss because of biting very hard objects. His two siblings from a non-consanguineous marriage were normal. There was no history of similar cases in the family of the mother or father. When queried, his parents explained that the child had achieved bladder control and had normal sweating. However, he did not demonstrate a normal reaction to foul smells. On examination, he had an active pressure ulcer of grade III over the anterior aspect of the right knee and a healing pressure ulcer of grade II over the left knee (Figure 2). There was a healed wound over the left elbow (Figure 3). The skin around the right big toe was thick, hard, and rough and had a crack over the right first metatarsophalangeal joint (Figure 2). His tongue was slightly bitten, and his lower incisors and canines were missing (Figure 4). He did not show withdrawal response to pinprick yet distinguished between hot and cold stimuli. His muscle tone and DTR were normal.

The patient's hemoglobin $(9.3 \mathrm{~g} / \mathrm{dL}$; normal: $13-17 \mathrm{~g} /$ $\mathrm{dL}$ ) and neutrophil percentage (37\%; normal: 40-80\%) were reduced. His platelet count $\left(562 \times 10^{9} / \mathrm{L}\right.$; normal: $150-400 \times$ $\left.10^{9} / \mathrm{L}\right)$, lymphocyte percentage (56\%; normal: $\left.20-40 \%\right)$, and erythrocyte sedimentation rate (ESR) $(18 \mathrm{~mm}$ at the first hour; normal: 0-9 $\mathrm{mm}$ at the first hour) were all raised. However, his total leucocyte count and serum uric acid level were normal. His NCS showed normal motor and sensory studies, and EMG was within normal limits. The patient was advised to undergo a sural nerve biopsy that turned out to be normal. Informed consent was obtained from the mother of the patient for the publication of this case report and the accompanying images.

\section{Case 3}

A 4-year-old boy presented with a two month history of pressure ulcers that had developed over the anterior aspect of both knees. He had a history of biting his right hand. His response

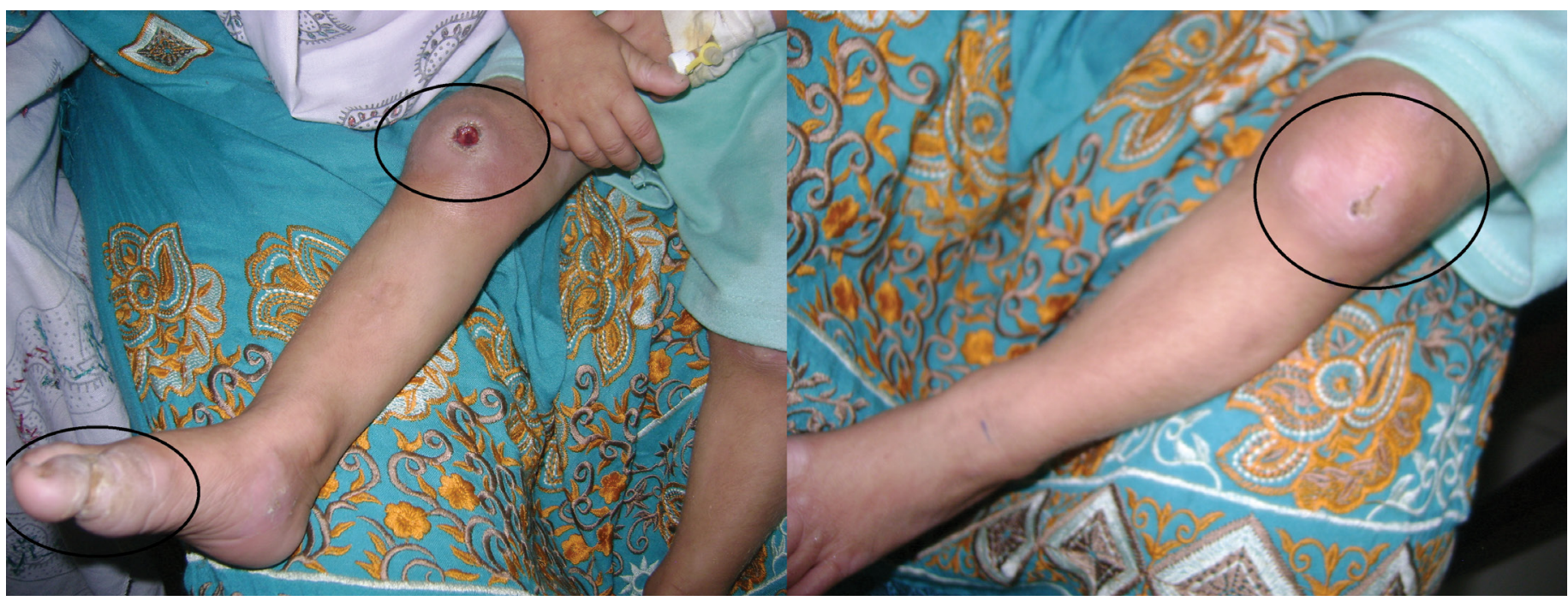

Figure 2. Second case: A 30-month-old male with an active pressure ulcer of grade III over the anterior aspect of the right knee and a healing pressure ulcer of grade II over the left knee. The skin around the right big toe is thick and hard with a crack over the right first metatarsophalangeal joint 


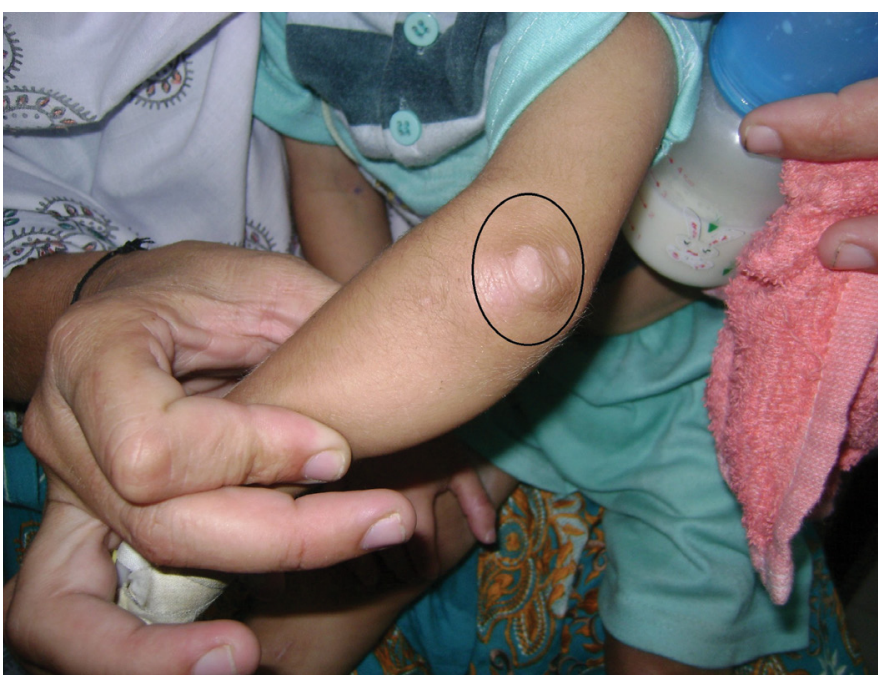

Figure 3. The second case with a healed wound over the left elbow

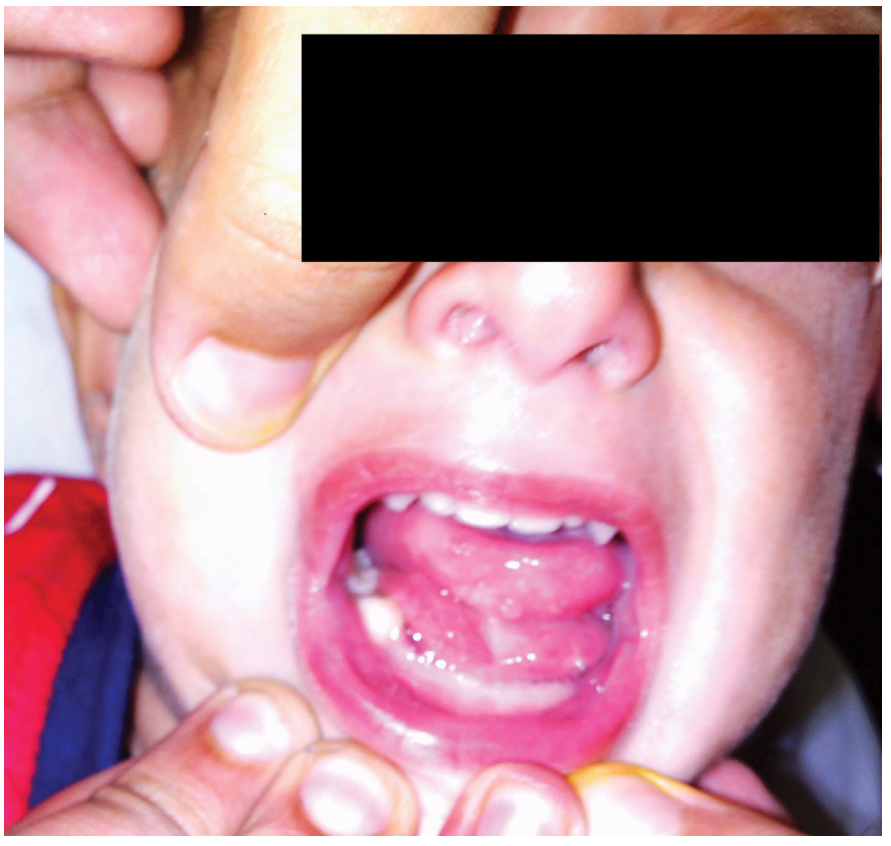

Figure 4 . The second case showing a bitten tongue and missing lower incisors and canines

to foul smells was previously abnormal. There was no history of urinary retention, incontinence, abnormal sweating, or dry eyes. His siblings from a non-consanguineous marriage were normal. On examination, he had excessive dribbling of saliva from the mouth. There were two active grade III pressure ulcers over the anterior aspect of both knees (Figure 5). Multiple abrasion marks were found over the legs (Figure 5). Major portion of the distal phalanges of his right index and middle fingers was missing (Figure 6). He had no withdrawal response to pinprick; however, he could distinguish between cold and hot stimuli. His muscle tone and DTR were normal.

The patient had a raised serum ESR $(16 \mathrm{~mm}$ at the first hour; normal: 0-9 $\mathrm{mm}$ at the first hour). His uric acid level was within

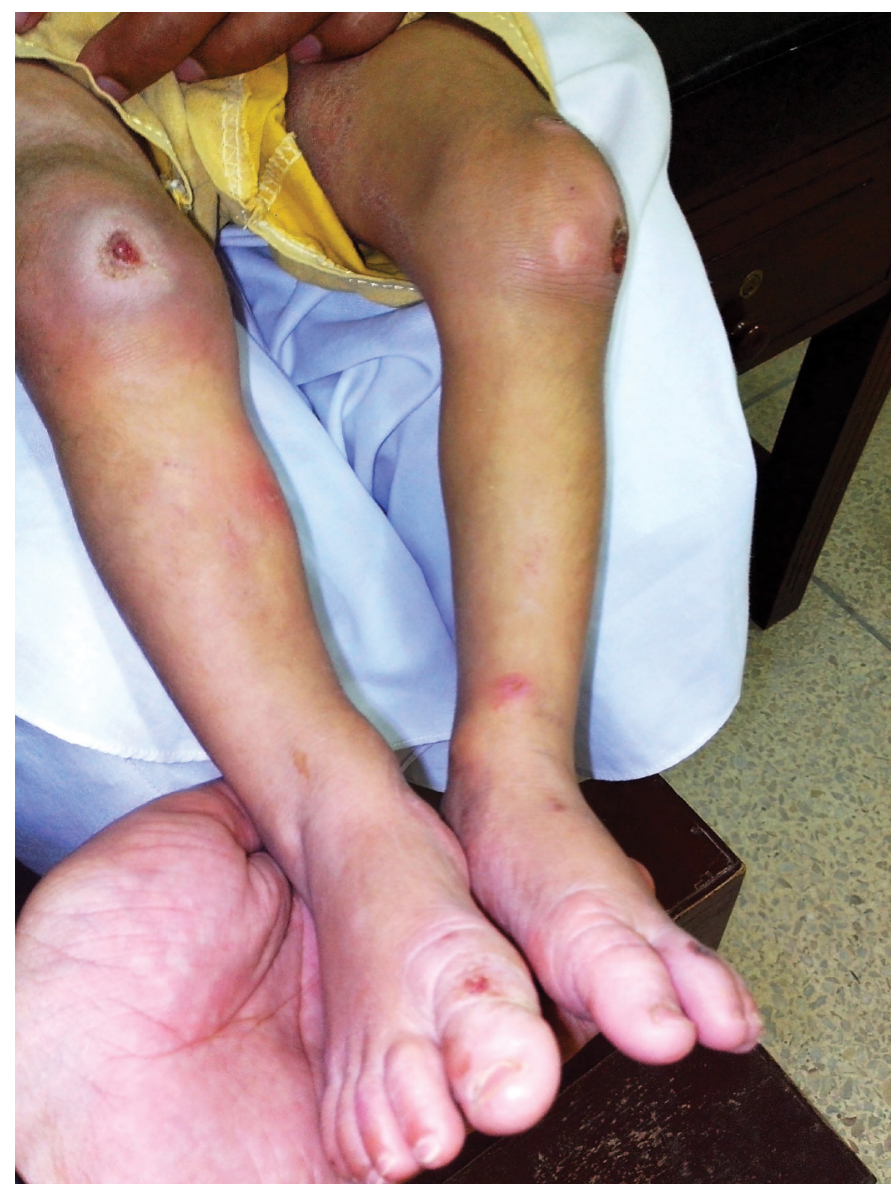

Figure 5. Third case: A 4-year-old boy with two active grade III pressure ulcers over the anterior aspect of both knees and multiple abrasion marks over the legs

normal limits. MRI of his brain was also normal. He had normal motor and sensory NCS in the upper and lower limbs. EMG was normal in all sampled muscles of the four limbs. The patient was also advised to undergo a sural nerve biopsy, but his parents did not agree because of financial constraints. Informed consent was obtained from the father of the patient for the publication of this case report and the accompanying images.

\section{Discussion}

The terms congenital indifference to pain and congenital insensitivity to pain (CIP) were used interchangeably until 1970, when they were distinguished and described as two distinct syndromes (1). In patients with CIP, the pain stimulus is not properly transmitted to the central nervous system due to an alteration of the structure or function of the sensory pathways that becomes evident as abnormalities on NCS and nerve biopsy (1,36). Nevertheless, reports of CIP cases with normal NCS have been described (7-10). In patients with congenital indifference to pain, the peripheral sensory pathways are intact and sufferers correctly perceive the nature of painful stimuli but fail to react in the normal defensive manner. Rather, they demonstrate a rise in pulse and respiratory rate and an upsurge in blood pressure 


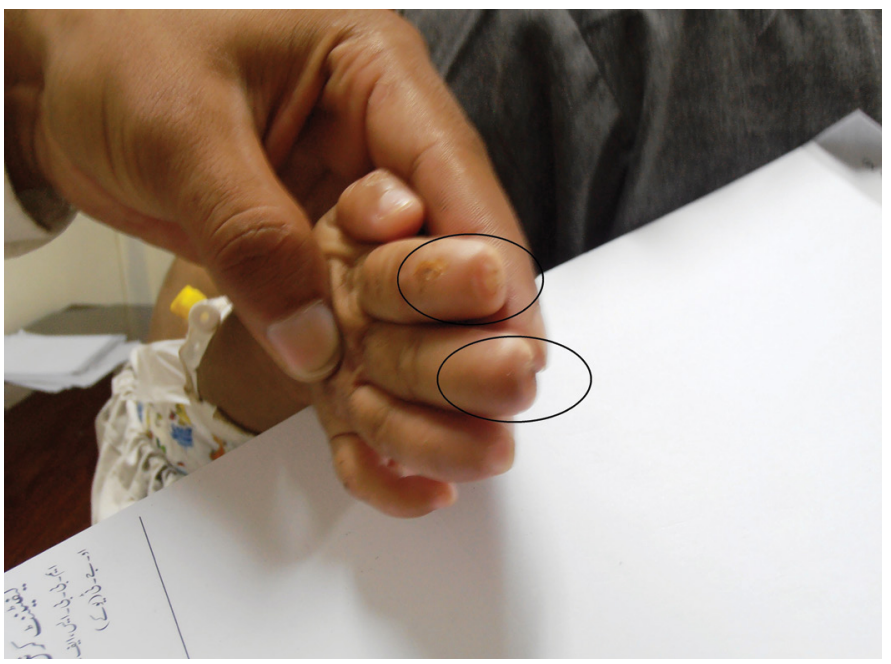

Figure 6 . The third case with a major portion of the distal phalanges of his right index and middle fingers missing

on exposure to painful stimuli (11). The only other significant clinical feature in this syndrome is the reduced or absent sense of smell $(4,12)$. The patients are not mentally deficient and have normal DTR and completely normal sensory examinations. The NCS in these cases is normal and the skin is normally innervated on histological examination $(1,11,12)$.

The cases of congenital indifference to pain become evident at early childhood with frequent fractures, ulcers, and burns. Sufferers are entirely unconcerned with their injuries and wounds. It has been suggested that these individuals have a deficit in their affective-emotional response to pain, rather than a deficit in their discrimination of painful stimuli (1). A few genetic studies have provided evidence that SCN9A genetic mutations affecting the sodium channel [ $\mathrm{Na}(\mathrm{v})$ 1.7] play the essential role in congenital indifference to pain $(4,14)$.

Congenital indifference to pain is generally considered a diagnosis by exclusion (15). Other differential diagnoses that should be considered in such patients include CIP, pain asymbolia, Fragile $X$ syndrome $(11,15)$, and syringomyelia. Patients with pain asymbolia have lesions in the somatosensory cortex, which generate deficits in the sensory-discriminative component of pain, and in the anterior cingulate and insular cortices that leads to the loss of the affective-emotional component of pain (13). Imaging studies are required to rule out this disorder.

Fragile $X$ syndrome is an $X$-linked recessive disorder characterized by short stature, a long narrow face with mid-facial hypoplasia, a large head and ears, mental retardation, and behavioral abnormalities. Children demonstrate self-injurious behavior; they scratch to produce wounds, bang their head, and bite themselves (11).

Syringomyelia presents with a loss of pain and temperature sensibility while light touch, vibration and position senses remain intact. Painless ulcers of the hands are frequent. Edema, hyperhidrosis, and Horner syndrome can occur due to the interruption of autonomic pathways (16). Less frequently, neuropathic osteoarthropathy, which affects shoulder, elbow, or wrist joints, may develop $(16,17)$. Impaired bowel and bladder functions usually occur as a late manifestation (16).

Patients from northern Pakistan have presented with phenotypes similar to congenital indifference to pain but have been diagnosed as having CIP on detection of a genetic defect in $\mathrm{Na}(\mathrm{v}) 1.7$ sodium channels (14). All patients discussed in the present report were diagnosed on the basis of clinical, electrophysiological, and histopathological findings to be suffering from congenital indifference to pain rather than CIP based on the evidence provided in previous reports $(1,3-6)$. The patients were brought to the institute with complaints of self-biting, but they did not have siblings affected by the syndrome. The latter two patients had active wounds over their knees; however, they were able to differentiate hot from cold sensations. Excessive dribbling of saliva was observed in the first and third patients. All patients had an abnormal response to painful stimuli and normal DTR. MRI brain scans performed in two patients were normal. NCS and EMG in all cases were normal. Sural nerve biopsy performed in one patient was also normal.

Congenital indifference to pain is a problem that is difficult to control and impossible to treat (11). Vigilance is required from parents to prevent recurrent injuries. An interdisciplinary team management approach should be promoted that includes the services of medical staff, rehabilitation physicians, psychologists, and physiotherapists.

Informed Consent: Written informed consent was obtained from parents of the patients who participated in this case.

Peer-review: Externally peer-reviewed.

Author Contributions: Concept - A.R.Q.; Design - A.R.Q.; Supervision - S.B.A.; Materials - A.R.Q., S.B.A., A.A.K.; Data Collection and/or Processing - A.R.Q., S.B.A., A.A.K.; Analysis and/or Interpretation - S.B.A.; Literature Review - S.B.A.; Writer - A.R.Q., S.B.A., A.A.K.; Critical Review - Z.A.G.

Conflict of Interest: No conflict of interest was declared by the authors.

Financial Disclosure: The authors declared that this study has received no financial support.

\section{References}

1. Nagasako EM, Oaklander AL, Dworkin RH. Congenital insensitivity to pain: an update. Pain 2003;101:213-9. [CrossRef]

2. Protheroe SM. Congenital insensitivity to pain. J R Soc Med 1991;84:558-9.

3. Rahalkar MD, Rahalkar AM, Joshi SK. Case series: Congenital insensitivity to pain and anhidrosis. Indian J Radiol Imaging 2008;18:1324. [CrossRef]

4. Goldberg YP, MacFarlane J, MacDonald ML, Thompson J, Dube MP, Mattice $M$, et al. Loss-of-function mutations in the Nav1.7 gene underlie congenital indifference to pain in multiple human populations. Clin Genet 2007;71:311-9. [CrossRef]

5. Dyck PJ, Mellinger JF, Reagan TJ, Horowitz SJ, McDonald JW, Litchy W], et al. Not 'indifference to pain' but varieties of hereditary sensory and autonomic neuropathy. Brain 1983;106:373-90. [CrossRef]

6. Klein C], Sinnreich M, Dyck PJ. Indifference rather than insensitivity to pain. Ann Neurol 2003;53:417-8. [CrossRef]

7. Kim JS, Woo YJ, Kim GM, Kim CJ, Ma JS, Hwang TJ, et al. Congenital insensitivity to pain with anhidrosis: a case report. J Korean Med Sci 1999;14:460-4. [CrossRef] 
8. Daneshjou K, Jafarieh H, Raaeskarami SR. Congenital Insensitivity to Pain and Anhydrosis (CIPA) Syndrome; A Report of 4 Cases. Iran J Pediatr 2012;22:412-6.

9. Ali N, Sharma S, Sharma S, Kamal Y, Sharma S. Congenital Insensitivity To Pain With Anhidrosis (HSAN Type IV), Extremely Rare Syndrome That Can Be Easily Missed By Bone And Joint Surgeons: A Case Report. Iran J Pediatr 2012;22:559-63.

10. Bowsher D, Geoffrey Woods C, Nicholas AK, Carvalho OM, Haggett $\mathrm{CE}$, Tedman B, et al. Absence of pain with hyperhidrosis: a new syndrome where vascular afferents may mediate cutaneous sensation. Pain 2009;147:287-98. [CrossRef]

11. Kapasi A, Trasi S, Khopkar U, Wadhwa S. Congenital indifference to pain. Indian J Dermatol Venereol Leprol 1992;58:273-6.

12. Hirsch $E$, Moye D, Dimon JH 3rd. Congenital indifference to pain: long-term follow-up of two cases. South Med J 1995:88:851-7. [CrossRef]
13. Karkashan EM, Joharji HS, Al-Harbi NN. Congenital insensitivity to pain in four related Saudi families. Pediatr Dermatol 2002;19:3335. [CrossRef]

14. Cox JJ, Reimann F, Nicholas AK, Thornton G, Roberts E, Springell $\mathrm{K}$, et al. An SCN9A channelopathy causes congenital inability to experience pain. Nature 2006;444:894-8. [CrossRef]

15. Adelaida Álvarez C, Aristizábal SP, Chaparro LE, Ramírez LJ, Sarassa CA. Indiferencia congénita al dolor. Revista Colombiana de Anestesiología 2010;38:528-35. [CrossRef]

16. Al-Shatoury HAH, Galhom AA, Wagner FC.MD. Syringomyelia: Emedicine. Available from: [http://emedicine.medscape.com/article/1151685.html]. Accessed on 10th March 2014.

17. Jones EA, Manaster BJ, May DA, Disler DG. Neuropathic osteoarthropathy: diagnostic dilemmas and differential diagnosis. Radiographics 2000;20 Spec No:S279-93. [CrossRef] 